\title{
Libertad como no-dominación * Freedom as Non-Domination
}

\author{
Ricardo Cueva Fernández \\ Universidad Autónoma de Madrid \\ ricardo.cueva@uam.es
}

Recibido / received: 26/11/2018

Aceptado / accepted: 11/03/2019

DOI: https://doi.org/10.20318/eunomia.2019.4704

\section{Resumen}

El neo-republicanismo es una propuesta principalmente articulada por P. Pettit (1999 [1997]), aunque se apoye en trabajos de carácter historiográficos previos realizados por otros autores. Pretende constituir un tertium genus en la filosofía política que sirva de opción distinta tanto al comunitarismo como al liberalismo. Sin embargo, las intenciones de Pettit acaban vaciando de contenido lo que sí que sería realmente una postura republicana que, al mismo tiempo que integrara la vieja visión de autores clásicos y los hallazgos de la historiografía contemporánea, pudiera unirlos al paradigma democrático.

\section{Palabras clave}

Republicanismo, libertad, autogobierno, comunidad política, no dominación.

\begin{abstract}
Neo-republicanism is a proposal mainly articulated by P. Pettit (1999 [1997]), although its grounds are previous historiographical works made by other authors. It aims to constitute a tertium genus in political philosophy that serves as a distinct option from both communitarianism and liberalism. However, Pettit's intentions end up emptying the content of what would really be a republican position that, at the same time as integrating the old vision of classic authors and the findings of contemporary historiography, could link them to the democratic paradigm.
\end{abstract}

\section{Keywords}

Republicanism, liberty, self-government, political community, non-domination.

SUMARIO. 1. Introducción. 2. Los auspiciadores. 3. El concepto de libertad y sus avatares. 4. Crítica.

\footnotetext{
* Este texto se enmarca dentro del proyecto DER2015-69217-C2-1-R, "Reforma constitucional: problemas filosóficos y jurídicos", financiado por el Ministerio de Economía y Competitividad del Gobierno de España.
} 


\section{Introducción}

El "republicanismo" tuvo un incierto futuro quizás ya desde su origen en la Antigüedad, pero su casi desaparición como término de debate en la teoría política se debió probablemente a la llamada Guerra Fría, que inauguró una etapa de enfrentamiento entre bloques a partir de la finalización de la segunda contienda mundial del siglo XX. $Y$ es que, en efecto, si revisamos aquel período histórico podremos observar, sin temor a equivocarnos, que precisamente los respectivos países que lideraban los dos lados de la citada división eran ambos "repúblicas" (en cuanto a formas de Estado). Y, al mismo tiempo, mostraban al planeta que gran parte de su liza se libraba en términos económicos: vencería aquel que pudiera ser hegemónico en uno y otro punto del planeta según los recursos materiales y humanos que pudiera movilizar para su causa. En este combate de dimensiones mundiales era difícil que pudiera abrirse paso con cierto sentido la vieja acepción que flotaba en los libros de Historia tan a menudo y que numerosos cronistas nos habían transmitido desde muchos siglos atrás, ya fuera en la versión más o menos escolástica de un Francisco Suárez, ya en la plenamente renacentista de Maquiavelo, ya en las de la de los revolucionarios franceses de 1789 o de ilustrados como Rousseau o Kant. Para colmo, la gran contienda de 1939-45 no se había librado entre repúblicas y monarquías, sino entre la democracia y el fascismo, al menos en términos de extensa difusión. La libertad, pues, un viejo concepto que los griegos identificaban con eleutheria y los romanos con libertas, había pasado a identificarse con otro tipo de lucha muy distinta a la de los antiguos.

Sin embargo, el concepto de república siguió latente y jugó también cierto papel en la reconstrucción europea debido a su prestigio democrático, tal y como pronto se percibiría en Italia con la celebración del referéndum correspondiente que daría paso a la Constitución de 1947. Pero fue sin duda precisamente a partir del derrumbe de uno de los dos bloques citados en 1989 cuando algunos pensadores de distintas disciplinas lo recuperaron para intentar dar respuesta al capitalismo triunfante y al "fin de la Historia". Por añadidura, el campo se hallaba especialmente abonado debido a un cierto agotamiento en la discusión entre liberales y comunitarios, proveniente ya de comienzos de los años ochenta, y en la que habían contribuido numerosos intelectuales, todos ellos tan renombrados como John Rawls, Ronald Dworkin, Michael Sandel, Michael Walzer, Alisdair Maclntyre, o Charles Taylor.

\section{Los auspiciadores}

Los neo-republicanos, pues, asomaron, primero de manos de la historiografía, su base logística principal, para adentrarse después en sustantivas discusiones sobre filosofía política, alentados a menudo por la propia asunción de muchos de sus presupuestos por anteriores autores que precisamente un poco antes se habían encuadrado entre los liberales o los comunitaristas. Así, el primero en abrir fuego fue quizás el historiador de Cambridge Quentin Skinner con su texto "The idea of negative liberty: Philosophical and historical perspectives" (1984), si bien sería Philip Pettit quien agruparía reflexiones en su Republicanism (1999) ${ }^{1}$. En realidad, y como puede comprobarse una vez más y al modo en el que había demostrado la discusión entre liberalismo y comunitarismo, de nuevo los autores principales emergían de la órbita anglosajona y se interesaban por conceptos y categorías al modo de Isaiah Berlin,

\footnotetext{
${ }^{1}$ El original apareció en 1997, bajo el título Republicanism. A Theory of Freedom and Government, en la editorial Oxford University Press.
} 
pero sobre todo por el contenido del valor libertad y su raigambre en la Historia. No podía ser de otro modo, además, considerando la propia tradición historiográfica que partiendo de América y el Reino Unido había contribuido a mantener la explicación "republicana" de la aparición de los mismísimos Estados Unidos. Así, no es difícil recordar estudios como los de la británica Caroline Robbins, quien ya en 1959 habría publicado su Eighteenth-Century Commonwealthman, y con ello desafiado la interpretación habitual de Louis Hartz y su volumen The Liberal Tradition in America $(1955)^{2}$. Bernard Bailyn tuvo aún mayor éxito y reconocimiento, en la misma línea que Robbins, con The Ideological Origins of the American Revolution (1967), y le siguieron Gordon S. Wood con The Creation of the American Republic, 1776-1787 (1969) y John G. A. Pocock con The Machiavellian Moment: Florentine Political Thought and the Atlantic Republican Tradition (1975). Todos estos historiadores pusieron de manifiesto que la ideología de los colonos era predominantemente republicana (frente a lo acaecido a partir de la emergencia constitucional de 1787), situando el bien común en un lugar preeminente, así como la virtud cívica y el autogobierno. De alguna forma, pues, los colonos norteamericanos habían sido antes republicanos que liberales en sus referencias ideológicas, e incluso aunque sus prácticas hubieran sido de carácter democrático en amplia medida, nunca se habían referido en demasía a tal tradición, entonces con escasos precedentes y de manera usual maltratada por los comentaristas, historiadores y pensadores de los que ellos mismos bebían.

\section{El concepto de libertad y sus avatares}

Skinner y Pettit propusieron así el concepto de libertad como "no dominación", si bien el primero más nítidamente desde la historia de las ideas y el segundo con aspiraciones mayores en la filosofía política, dando origen de este modo a toda una estela de autores entre los que podríamos destacar a Dagger (1997), Ferrara (2006), Gargarella (2005), Gibson (2000), Habermas (1994), Herzog (1986), Honohan (2002), Isaac (1988), Klappenbach (2003), Maynor (2003), Olfield (1990), Rahe (1994), Sunstein (1988) o Viroli (1995), por citar solo a unos pocos.

Sea como fuere, el análisis que realizan tanto Skinner como Pettit insistió en que la dependencia no solo suponía una mera disminución de la seguridad a fin de disfrutar de la libertad, sino de la propia libertad en sí misma (Skinner, 1998: 84). La libertad se erigiría así sobre la fuente del poder, no sobre su extensión, algo que sí preocuparía en cambio más al liberalismo, y ello de acuerdo con el ámbito de la denominada libertad negativa señalada por Isaiah Berlin en sus Dos Conceptos de Libertad (1958: 122-131). En palabras de Pettit:

"la distinción libertad negativa-positiva ha hecho un mal servicio al pensamiento político. Ha alimentado la ilusión filosófica de que, detalles aparte, solo hay dos modos de entender la libertad: de acuerdo con el primero, la libertad consiste en la ausencia de obstáculos externos a la elección individual; de acuerdo con el segundo, entraña la presencia, y normalmente el ejercicio de las cosas y las actividades que fomentan el autodominio y la autorrealización: en particular, la presencia y el ejercicio de las actividades participativas y de sufragio, merced a las cuales los individuos pueden unirse a otros en la formación de la voluntad común, popular” (Pettit, 1999: 37).

La propuesta neo-republicana, pues, se centraría en la adopción de mecanismos que sirvieran para preservar la libertad, abarcando tanto procedimientos específicos como el ejercicio de la virtud cívica, pues de no ser así la comunidad

\footnotetext{
2 Siguiendo así a C. L. Becker y The Declaration of Independence. A Study on the History of Political Ideas, New York, Harcourt, Brace and Co., 1922. Becker, al igual que Hartz, había sostenido sin embargo que John Locke y su Segundo Tratado sobre el Gobierno Civil constituían la principal inspiración de la emancipación estadounidense.
} 
política decaería por causa de una corrupción que crecería de forma imparable. Instituciones como aquellas que separan distintas instancias de poder (ya fueran las tradicionales de Montesquieu, la rotación de cargos típica del pasado, las de carácter federal o incluso otras nuevas) y el compromiso de la ciudadanía con ellas serían las que servirían para conservar la república.

\section{Crítica}

¿En qué medida se distancian estas propuestas, que algunos tachan de republicanismo "instrumental" (Honohan, 2002: 8 y 9, 55 y 56, 151 y 152, y Maynor, 2003: 23), del liberalismo al modo rawlsiano? Alan Patten indicó al respecto en un artículo de 1996 que ninguna participación particular individual era rigurosamente necesaria para la conservación de la libertad (1996: 29), y que por ello Rawls, e incluso Kant anteriormente, habían introducido la hipótesis contractual (en el caso del primero, mediante la llamada "posición original"). El autor de $A$ Theory of Justice ya habría hablado así, de que para que una sociedad fuera justa era necesario que los ciudadanos poseyeran un "profundo deseo, normalmente eficaz", de actuar según exigieran los principios de la justicia (ibid.: 31, cit. de Rawls, 1971: 502), que se corresponderían a su vez con la concepción pública de esa misma sociedad (1971: 21, 159 y 269). Es más, Rawls también se refería en su Theory of Justice a cierta necesidad de educación cívica y de instituciones que la incentivaran, e incluso a la de que las leyes protegieran el sistema completo de libertad restringiendo la de tipo particular (ibid.: 33 y 267). De hecho, las aportaciones de Pettit parecían bastante escasas al lado del propio esfuerzo rawlsiano por limar las aristas más individualistas de su Teoría, con el auxilio de Kant. El volumen de Republicanismo no mostraba diseño institucional alguno para la profundización en la democracia, apelando en cambio a indefinidos mecanismos de "disputabilidad" (Pettit, 1999: 242), susceptibles de convertirse en simples consultas en el mejor de los casos o, en el peor, en negociaciones de la autoridad pública con los consabidos lobbies.

Por tanto, cabe preguntarse con mayor profundidad qué aportaría el republicanismo a la filosofía política más allá de un puñado de mecanismos o buenos deseos de ser un tertium genus, de qué manera formula algún o algunos aspectos, en caso de que así lo hiciera, que le convirtiesen en algo verdaderamente distinto a otras opciones o corrientes hoy en vigor. Como se ha podido comprobar, muchos de sus componentes - de forma muy evidente el supuesto de la división del poder- han sido asumidos por el liberalismo (sin duda el de Rawls, pero quizás también el de Hayek), y también por los Estados "constitucionales". Y, sin embargo, hay otros rasgos que quizás lo puedan aproximar, al menos intuitivamente, a ciertas acepciones más fuertes del término comunidad, y justo en una línea en que ninguno de los contractualistas "develarían" (por mucha "ignorancia" que evitasen).

Y es que, si el republicanismo alude al autogobierno de un colectivo, parece claro que tal operación no tiene por qué pasar por el filtro de ningún "acuerdo de voluntades" entre individuos, de carácter previo. Esta operación artificial e hipotética es, desde luego, la expresión de un intento sofisticado por parte de numerosos autores de abrir paso a un concepto de libertad determinado y originado en cierto momento histórico para dar salida a las pretensiones universales de una razón abstracta y aérea, dispuesta a hacer tabla rasa de sociedades con distintas referencias morales y culturales. Pero por eso mismo no consigue captar la continuidad de las comunidades. De alguna forma, parece que no pudiera engendrarse autodeterminación colectiva alguna anclándose solo en cierta noción de la elección racional que no considere las prácticas sociales acumuladas por el grupo social a lo largo del tiempo y que le pudieran hacer consciente de su común aspiración a convivir y de hacerlo en pos de futuro y de reconocimiento. Recordemos que los 
estudios de Skinner, en esto significativamente más avezados que los de Pettit, insisten en la noción de "independencia" que va adosada a la república. La libertad personal en una república no queda articulada alrededor de una opción entre iguales, sino de una práctica entre ellos, principalmente política pero también cultural y moral, en la que los individuos se reconocen entre sí en pie de igualdad y pretenden asimismo ese reconocimiento hacia el exterior de la comunidad.

Dicho todo esto, ¿en qué medida se mantiene vivo el republicanismo en sociedades como las nuestras, en las que su referencia a menudo ha tenido que ser desempolvada acudiendo a la Historia, como ya se ha visto? Precisamente por la vía de agua que supuso en el liberalismo la forma política democrática. La democracia, así, rescata la soberanía, el fundamento republicano principal, aunque sea de manera que la práctica política del pueblo se encuentre en tensión habitual con una formulación de ésta en términos de derechos, lenguaje favorito del liberalismo (y quizás a esto quiera hacer frente Habermas con su tesis de la cooriginalidad, 1994: 767). Pettit se equivoca sin duda cuando dice que "aun cuando la tradición republicana halle valiosa e importante la participación democrática, no la considera un valor básico inconmovible" (1999: 25), pues de esta forma le resta al republicanismo su fuerza principal de apoyo y articulación alternativa a la liberal. O quizás lo que suceda es que ni él ni otros de los autodenominados republicanos lo sean realmente: acuñar la "no dominación" puede que no valga de mucho si no ponemos en claro cuál es el objeto del dominio.

\section{Bibliografía}

BAILYN, B. (1967), The Ideological Origins of the American Revolution, Harvard University Press, Cambridge.

BERLIN, I. (1969), "Two Concepts of Liberty" (1958). En: BERLIN, I, Four Essays on Liberty, Oxford, Oxford University Press, pp. 118-172.

CICERÓN, M.T. (1986), Sobre la República. Sobre las leyes; trad. cast. de José Guillén, Tecnos, Madrid.

DAGGER, R. (1997), Civic Virtues. Rights, Citizenship, and Republican Liberalism, Oxford University Press, New York.

FERRARA, A. (2006), "El desafío republicano", Claves de la Razón Práctica, núm. 139, pp. 4-12.

GARGARELLA, R. (2005), "El carácter igualitario del republicanismo", Isegoría, núm. 33, pp. 175-89.

HABERMAS, J. (1994), "Human Rights and Popular Sovereignty. The Liberal and Republican Versions", Ratio Juris, Vol. 7, núm. 1, pp. 1-13.

HARTZ, L. (1955), The Liberal Tradition in America, Harcourt \& Brace, New York.

HERZOG, D. (1986), "Some Questions for Republicans", Political Theory, vol. 14, núm. 3, pp. 473-493.

HONOHAN, I. (2002), Civic Republicanism, Routledge, London.

KLAPPENBACH, A. (2003), "El liberalismo angélico y las sendas de elefantes", Claves de la Razón Práctica, núm. 135, pp. 79-82

MANIN, B. (1997), The Principles of Representative Government, Cambridge, Syndicate of the Press of the University of Cambridge, Cambridge.

MAYNOR, J.W. (2003), Republicanism in the Modern World, Polity Press, Cambridge.

OLFIELD, A. (1990), Citizenship and Community. Civic Republicanism and the Modern World, Routledge, London.

PETTIT, P. (1999 [1997]), Republicanismo. Una teoría sobre la libertad y el gobierno, trad. cast. de Toni Doménech, Paidós, Barcelona.

POCOCK, J.G.A. (1975), The Machiavellian Moment. Florentine Political Thought and the Atlantic Republican Tradition, Princeton University Press, London. 
RAHE, P.A. (1994), Republics Ancient and Modern, 3 vols., University of North Carolina Press, Chapel Hill.

RAWLS, J. (1971), A Theory of Justice, Harvard University Press, Cambridge.

ROBBINS, C. (1968), The Eighteenth-century Commonwealth man. Studies in the Transmission, Development, and Circumstance of English Liberal Thought from the Restoration of Charles II until the War with the Thirteen Colonies, Harvard University Press, Cambridge.

SANDEL, M. (1996), Democracy's Discontent. America in Search of a Public Philosophy). Harvard University Press, Cambridge.

SKINNER, Q. (1984), "The idea of negative liberty: Philosophical and historical perspectives". En: RORTY, R., SCHNEEWIND, J. y Q. SKINNER (eds.), Philosophy in History. Essays in the Historiography of Philosophy, Cambridge, Cambridge University Press, pp. 193-222.

SKINNER, Q. (1998), Liberty before Liberalism, Cambridge University Press, Cambridge.

SUNSTEIN, C. R. (1988), "Beyond the Republican Revival", Yale Law Journal, vol. 97, pp. $1539-1590$.

VIROLI, M. (1995), For Love of Country, Oxford University Press, Oxford.

WOOD, G.S. (1969), The Creation of the American Republic (1776-1787), University of North Carolina Press, Chapel Hill. 